\title{
Solidariedade, Política e Poder: o desafio às Políticas Sociais*
}

CARLOS HENRIQUE ASSUNÇÃO PAIVA ${ }^{l}$

Este artigo discute alguns significados atribuídos à solidariedade, privilegiando-se aqueles, nos quais mais fortemente se verifica a preocupação com o tema do amparo e da justiça social. Por esse motivo, atentou-se aos intelectuais que podem ser situados, desse ponto de vista, em uma corrente de pensamento voltada para o tema da democracia, incorporação e coesão social. Propõe-se que o problema da falta de coesão social esteja relacionado com o declínio dos sistemas e instituições de amparo e assistência social nas sociedades ocidentais modernas. O autor mostra que é da idéia de solidariedade no espaço e no tempo que parece surgir a possibilidade de uma forte coesão na vida em sociedade.

Palavras-chave: Solidariedade social; políticas públicas; assistência social. 


\section{Introdução}

Neste trabalho, discuto a relação entre o esfacelamento dos laços sociais ou comunitários e as políticas públicas, sociais e assistenciais implementadas pelos governos ocidentais, comunidades e grupos sociais, na crise do keynesianismo. Trata-se de uma crítica ao modelo imposto e sustentado pela ideologia do liberalismo, sem no entanto entrar no campo de batalha dos economistas. Meu terreno é o da sociologia, da história e da psicologia social. Minha hipótese é que na esfera do discurso econômico neoliberal vigente, o qual sustenta que o indivíduo dispõe de liberdade individual e autonomia, forja-se a responsabilidade de cada um perante sua própria vida, ao mesmo tempo em que se promove a redução do papel e responsabilidade do Estado na construção de uma sociedade mais justa e solidária.

Nesse contexto, surge como tendência uma forte redução ou enfraquecimento na intervenção das políticas sociais ou assistenciais, além de ocorrer um significativo esvaziamento da esfera política. Cabe somente ao indivíduo sua manutenção e superação: é o "cada um por si" de nosso tempo.

Para isso, abordarei (1) a obra $L$ 'esprit du don, de Jacques Godbout, cujo argumento central sustenta que tanto o mercado como o Estado seriam os principais responsáveis pela diluição dos papéis sociais, da sociabilidade e da solidariedade social; (2) as teses de Eric Hobsbawm sobre a ação do Estado na gerência das sociedades e sua repercussão sobre os vínculos sociais; e, por último, (3) o trabalho de Gösta EspingAndersen, em Politics against markets, cuja tese sustenta que os partidos políticos têm um papel-chave na constituição das políticas sociais, dos vínculos sociais, do universalismo e da solidariedade em todo o mundo ocidental.

\section{A Sociedade}

O ponto de vista de Jacques Godbout acerca da sociedade guarda semelhanças com o que Norbert Elias concebeu em A sociedade dos individuos alguns anos antes. Para ambos, o termo "sociedade" é, na vida moderna, utilizado como se referindo a uma pessoa ou a uma força hostil, restritiva e opressora, que negaria a satisfação do indivíduo e o obrigaria a refrear dentro de si tudo aquilo que gostaria de fazer ou expressar. Nesse contexto, segundo o autor de L'esprit $d u$ don, a relação social só poderia significar um fardo na vida dos indivíduos, pois a idéia de "obrigação social" estaria a todo momento contaminada por uma concepção de "liberdade" ligada às noções de controle e opressão sociais. Em sua perspectiva, essa concepção 
equivocada colocaria em xeque a sociabilidade e a trama das relações sociais, em nome da capacidade ilimitada de autodeterminação dos indivíduos.

Não resta dúvida de que o autor toca numa ferida cuja infecção e cicatrização atormentam intensamente as sociedades democráticas modernas. Nelas, a questão da liberdade individual é princípio, com toda justiça esse não é o ponto - inabalável. Os olhos de Godbout se viram não exatamente para as implicações políticas da idéia de liberdade e, embora não as desconsidere, ele estende para além. $\mathrm{O}$ autor aborda o mundo das práticas silenciosas e cotidianas da cultura. Por exemplo, na oração "os amigos são melhores que a família, pois se pode escolhê-los", leia-se também, do ponto de vista do autor, "os amigos são melhores porque mais facilmente se pode abandoná-los".

A questão é, para o autor, que as relações familiares, como todas as relações sociais, têm como pano de fundo certos papéis e práticas sociais tradicionais que, segundo ele, parecem insuportáveis para determinados indivíduos modernos, especialmente se comparada à fluidez das relações sociais entre "amigos". O "ficar", prática social corriqueira das juventudes metropolitanas ocidentais, pode ser interpretado, nesse caso, como uma relação social - mesmo quando sexual — em que os indivíduos se destituem de "obrigações" para com o outro. São relações meramente voláteis. O que chama a atenção para Godbout é que o problema moderno da coesão social e da liberdade implicam a todo momento risco de abandono.

Não se trata do choque de um simples "voluntarismo" pessoal de cada indivíduo para com uma realidade social externa. É o indivíduo que foi educado ou formado para validar suas iniciativas perante uma realidade íntima, em oposição a um mundo social opressor e fugaz. Crer nos papéis sociais é crer nas obrigações, mas não como "obrigação", e sim como ato voluntário. Para o autor, a "obrigação" não é uma simples tarefa imposta pelas normas e condutas sociais. A obrigação é, para ele, a liberdade de estabelecer relações de dar, receber e retribuir. Foge ao sentido fixado pelo utilitarismo moderno. A questão que o autor propõe é: por que afinal se faz tanto esforço para se abandonar esta última conotação?

A tese de Godbout sugere que a constituição do mercado conduziu uma tendência crescente para liberar os membros das sociedades de toda obrigação ligada às relações sociais, a partir do paradigma de que todo lugar obrigatório poderia ser substituído por um bem ou serviço. Nesse caso, por exemplo, o papel de um filho que proveria e prestaria assistência social aos pais, seria substituído por um leque de profissionais pagos pelo Estado ou pela 
iniciativa privada. Isto ocorre porque o mercado busca sobretudo assegurar a circulação das coisas, mais especificamente a passagem do produtor para o consumidor, estabelecendo relações despersonalizadas entre indivíduos. Pretende, nesse caso, levar a cabo a utopia de destituir os papéis sociais em favor de "profissionais", que agiriam via mecanismos de "preços" estabelecidos, não pelos agentes, mas pelas próprias leis de mercado.

É uma realidade inteiramente nova, se comparada às chamadas sociedades primitivas. Com a chegada do mercado, as coisas não são mais fabricadas para alguém que necessariamente precisa, mas sim fabricadas por serem indiretamente úteis ao fabricante. Necessidades são criadas a milhares de desconhecidos, e o mercado é liberado de toda subordinação pessoal ("amigos, amigos, negócios à parte").

Nesse triunfo do indivíduo sobre a sociedade ${ }^{2}$, os seres humanos se transformaram em números e índices estatísticos. É uma revolução social não só porque as texturas sociais começaram a ser abaladas, mas também porque, ao serem, os padrões de comportamento das pessoas umas com as outras (seus papéis) se tornaram imprevisíveis. A insegurança surgia muitas vezes pela falta de convenções sociais, pela perda da expectativa ou previsibilidade do comportamento do "outro". Na perspectiva de Richard Sennett (1995), o "estrangeiro" transformou-se em "estranho".

Embora não completamente solapadas, as antigas convenções sociais e tradições culturais sofreram certo abalo em suas estruturas (Hobsbawm, 1995). Para um mundo onde boa parte da humanidade beneficiava-se da rede de parentesco, amizade e vizinhança para sobreviver economicamente, e mesmo fisicamente, o fato trouxe preocupações justificadas.

$\mathrm{Na}$ leitura de Godbout, os que usufruíam de aposentadorias, sistemas previdenciários ou de cuidados em lares geriátricos pareciam liberar os filhos e familiares da "obrigação" de cuidar deles. Isso porque, segundo o autor, o discurso político moderno está de acordo com a idéia de liberação do indivíduo para o ato voluntário, para que execute o "verdadeiro papel" escondido, mas predestinado pelo seu próprio self. O indivíduo se "encontraria" ao se destituir de toda carga social (regras, normas e condutas previstas socialmente).

Vale observar que o fenômeno não se realiza homogeneamente. Há circunstâncias históricas e sociais particulares e regionais que determinam um maior ou menor grau de "modernidade" e coesão social. Há movimentos, práticas sociais e culturais diferenciadas que não estão em sintonia com o utilitarismo, sobretudo na América Latina, onde o mercado, felizmente, não permite aos indivíduos se liberarem de tudo (Godbout, 1992). 
As resistências podem efetuar-se em diferentes planos. As que chamam mais a atenção, naturalmente, são aquelas que têm repercussões políticas mais sérias, pois são a encarnação, muitas vezes, de movimentos sociais organizados contra a "modernidade" ou o Ocidente. Segundo Edward Said (1985), a maior expressão ou o marco mais radical do nacionalismo foi alcançado com a oposição de Gandhi ao modelo de civilização apresentado pelas sociedades ocidentais. Influenciado por pensadores antimodernos, como Tolstói, Gandhi buscou colocar-se epistemicamente fora do pensamento iluminista ocidental.

O fato é que o indivíduo que nasce em determinado grupo, como propõe Émile Durkheim, em Da divisão do trabalho social, seja uma família, uma cidade ou mesmo um país, tenderá a raciocinar, sentir ou desejar como seus pares. A visão de mundo de sua comunidade será, pelo menos em parte, sua natureza mais íntima. Se há, nesse caso, uma cultura política e moralmente organizada a favor de relações humanas não instrumentalizadas, seus representantes, enquanto a cultura for hegemônica, tenderão a se portar de maneira altruísta. É o que se realiza freqüentemente em determinadas culturas ou segmentos sociais e em outros não. Uns nascem geneticamente mais altruístas que os outros? Certamente não ${ }^{3}$. Nas palavras de Cornelius Castoriadis (1982, p. 180), "imagem do mundo e imagem de si mesmo estão evidentemente sempre ligadas".

A fé do autor está, nesse caso, semelhante a Émile Durkheim, na capacidade de uma certa autogerência da vida social. Para ele, a estrutura ou o sistema da dádiva seria capaz de garantir a coesão e solidariedade sociais, mesmo num período em que a presença e a intervenção do Estado tenhamse tornado um elemento essencial para manutenção das garantias e ordens sociais. A questão inevitável que surge é: no momento em que o Estadoprovidência vem sendo questionado, via, naturalmente, argumentos econômicos e utilitaristas, que sistemas poderão dar garantias sociais às pessoas? Estarão elas condenadas ao desamparo? O sistema da dádiva em seu estado atual supriria, como propõe Godbout, a intervenção do Estado e garantiria a coesão social e a implementação de políticas públicas efetivas no campo da assistência social e da saúde?

\section{O Estado}

Eric Hobsbawm fez ver em Era dos extremos que, exatamente após a Grande Depressão de 1929, e principalmente após a Segunda Grande Guerra, houve uma explosão de Welfare States em escala mundial - é claro 
que, nesse contexto, uns deram mais ênfase ao State do que propriamente ao Welfare. Mas, o fato é que, de maneira geral, sobretudo nos países industrializados, surgiram amplos Estados previdenciários que tinham, num só tempo, um argumento econômico e um político a favor de suas práticas políticas. Segundo Maynard Keynes (1883-1946), a melhoria nas condições de vida dos trabalhadores beneficiados com o pleno emprego se repercutiria positivamente nas economias em recessão (ver Hobsbawm, 1995). Além disso, o desemprego era visto como um elemento explosivo de revoltas e agitações sociais. Num só lance, segundo os argumentos keynesianos, os governos dos Estados nacionais atenderiam as expectativas econômicas e políticas: mercado e controle social.

Do ponto de vista político-econômico, ocorreram grandes disparidades nesse modelo entre diversas regiões do globo. A Comunidade Européia, por exemplo, aceitou a responsabilidade pela manutenção e desenvolvimento de parte de seu território. As regiões mais atrasadas, como Portugal, foram subsidiadas pelas regiões mais ricas e com mais recursos econômicos e financeiros. $\mathrm{O}$ ingresso na comunidade, naturalmente, obedeceu mais a critérios político-econômicos que eminentemente geográficos, pois só foram admitidos, como membros, Estados cujo atraso não significasse um fardo demasiadamente insustentável a toda comunidade ou ao poder central. Ocorreu o que Hobsbawm $(1995$, p. 416) chamou de "egoísmo coletivo", pois a "verdadeira questão era o desejo da região rica de manter seus recursos para si mesma".

Para Hobsbawm, o Estado de Bem-estar foi visto como um mecanismo político capaz de realizar o altruísmo que na esfera social das relações humanas parecia irrealizável. Ele distribuiria, organizaria, repartiria bens e serviços entre os membros da sociedade. Ele progressivamente substituiria todas as formas tradicionais de relações humanas, pois surgira como a encarnação real da esfera pública (que permanecia diluída e enfraquecida nas relações sociais cotidianas). O Estado era a própria Sociedade.

A partir, principalmente, da década de 70, no entanto, os keynesianos começaram a sofrer forte oposição dos economistas neoliberais. Estes acreditavam que a melhor maneira de enfrentar as crises econômicas, especificamente o surto inflacionário, não era via altos salários, pleno emprego ou garantias sociais fixadas pelo Estado (como acreditavam os keynesianos), mas que esses "investimentos sociais" diminuíam as fatias de lucros e receitas, tanto do governo quanto das empresas privadas. Partiram do princípio que o mais importante para o desenvolvimento econômico de um país não 
era exatamente a melhoria das condições financeiras e econômicas de seus cidadãos, mas o lucro das empresas, como a locomotiva do progresso social.

O historiador Eric Hobsbawm não escondeu em sua obra o seu saudosismo em relação ao modelo de Estado e governo implementado pelos keynesianos. Para ele, aquele modelo caracterizou toda uma era de ouro e prosperidade nas sociedades industrializadas do Ocidente. Do seu ponto de vista, as políticas do Estado de Bem-estar poderão deixar saudades no sombrio e descontrolado modelo político-econômico que se estabelece no final do século XX.

Além do mais, como lembra Hobsbawm, a médio prazo isso colocaria o seguinte problema político: quem seriam as autoridades responsáveis pelas decisões? Seriam nacionais, comunidades étnicas, religiosas, supranacionais, globais? Difícil de responder.

$\mathrm{O}$ fato é que as políticas econômicas neoliberais foram historicamente construídas diante de uma certa concepção reducionista de sociedade. Para os neoliberais, a sociedade nada mais seria que a soma quantitativa de seus integrantes. Nesse caso, os números pareciam revelar com fidelidade todas as sutilezas das dinâmicas sociais, pois todos os indivíduos seriam partículas em competição a defender seus próprios interesses em um grande mercado livre de qualquer controle alheio a sua própria natureza ou dinâmica.

Nesse contexto, é lógico que a questão fundamental não é se o Estado possui ou não empresas produtivas, ou se mesmo possui empresas. $\mathrm{O}$ ponto central reside exatamente no papel que deveria cumprir no mundo público. O mercado, nos moldes modernos, se auto-regularia e a "mão invisível" desempenharia o papel de distribuidor de riquezas e justiça social? Ou ainda, compete ao Poder Público esse papel central na administração das incertezas e interesses coletivos?

O ponto é que a questão política da gerência e administração das sociedades continua na pauta de discussões dos intelectuais do final do século $\mathrm{XX}$. Tanto as perspectivas estruturalista, funcionalista, como comunitarista, parecem não ter fornecido respostas inteiramente adequadas para as surpreendentes realidades sociais do final desse século. Naturalmente, certas questões continuam pendentes, mas a riqueza das abordagens não deve ser desprezada. Daniel Bell, em The coming of post-industrial society, sobretudo, desloca a tônica do modo de produção, como fator desencadeador de problemas e transformações sociais para as mudanças provenientes do desenvolvimento técnico e tecnológico. Mais atento à complexidade da vida social do final do século, Bell organiza conceitos que levam em consideração 
e privilegiam tanto as transformações no mundo do trabalho como o advento de novos segmentos sociais. Em certo sentido, Bell atualiza a utopia.

A questão ainda mal resolvida é se o Estado pode realmente ser considerado um elemento alternativo e dispensável nas diferentes realidades sociais do final do século XX. O declínio da organização estatal significará, como argumenta Daniel Bell, uma expansão das fronteiras de realização do Poder? Eric Hobsbawm diria: democracia com exclusão social? Que instituições se responsabilizariam pela execução das políticas públicas?

Parece evidente que a coletivização da atenção ou do tratamento coletivo dos problemas da vida em sociedade não precisem necessária e inevitavelmente tomar a forma de instituições estatizadas. Embora historicamente se reconheça que, em determinados contextos, essa forma se tenha revelado nos últimos tempos a mais viável e de certa eficácia perante os problemas de distribuição de riqueza e assistência social em diversas regiões do planeta.

É provável que, na aurora do processo de constituição dos Estados e do mundo moderno, os indivíduos tenham rejeitado a possibilidade de vislumbrar uma autonomia absoluta diante das práticas sociais, econômicas, políticas e culturais de seu tempo e mesmo de eventos passados. Essa percepção reclamou, inevitavelmente, uma ação coletiva. O altruísmo, nesse caso, não descartaria e não seria a negação de problemas pessoais ou existenciais, mas, de fato, os transformaria em públicos: o problema de cada um individualmente teve, ou poderia ter, relação com a realidade dos "outros". Esse ponto de vista é uma certa consciência pública da interatividade social que inaugura o aparelho burocrático estatal ${ }^{4}$.

Olhando na mesma perspectiva, pior que a destruição de instituições públicas de intervenção no espaço público, preconizada pelos políticos e ideólogos do liberalismo atual, é o declínio da consciência que lhe deu vida e vitalidade, pois sem ela não há possibilidade de instauração do público e do coletivo. Sem interação, segundo Bell, não há vida.

\section{Mobilização Política e Solidariedade Social}

$\mathrm{O}$ advento da sociedade de massas alterou não apenas os comportamentos, hábitos e tradições sociais, mas também transformou a natureza dos sistemas políticos em que as sociedades estavam organizadas. Nesse contexto, o advento do sufrágio universal, por exemplo, alterou radicalmente o controle do poder político. A partir de 1871, vale lembrar, houve uma significativa expansão do direito de voto masculino nas sociedades européias, a 
começar pela sociedade francesa e pelo Império Alemão, seguindo-se pela Suíça, em 1874; Espanha, em 1890; Bélgica, em 1893; Holanda, em 1896; e pela Noruega, em 1898 (Barraclough, 1973, p. 123).

Essas mudanças sinalizaram o advento de inovações estruturais importantes que resultaram na forma democrática contemporânea de representação política: os partidos políticos. O elemento básico e indispensável nesse sistema estava ligado à idéia de que os eleitores não escolheriam o candidato exatamente por sua personalidade ou por suas características pessoais, mas pelas idéias e teorias que o político representaria no universo político-ideológico de determinada sociedade. Nesse caso, um candidato não só representaria uma idéia ou uma doutrina, mas também uma coletividade.

Segundo Adam Przeworski (1987), o envolvimento do movimento socialista com instituições burguesas, como o voto, não era desprovido de tensão e debates. No entendimento de muitos militantes, a partir do final do século passado, tal envolvimento ameaçaria objetivos políticos e sociais fundamentais ao próprio socialismo. Em primeiro lugar, muitos compreendiam que o partido não conseguiria governar sozinho, apesar de um provável, amplo e gradual apoio das massas trabalhadoras, o que o obrigaria a realizar alianças que "contaminariam" o caráter revolucionário das transformações sociais desejadas. Em segundo lugar, a idéia de massas representadas por líderes políticos desmobilizaria, na visão de alguns, a ação e os próprios interesses e anseios das massas. Há, nessa percepção da realidade social e política, um impasse jamais resolvido.

$\mathrm{O}$ argumento central de Gösta Esping-Andersen, em Politics against markets, é que enquanto os partidos socialistas forem concebidos estritamente como movimentos de classe - no caso dos socialistas como movimento trabalhador -, estarão sempre condenados à ruína. Segundo o autor, o impasse proposto pelos marxistas ortodoxos na idéia de guetto party estaria inevitavelmente em pauta: mesmo quando inteiramente mobilizados, os partidos socialistas não obteriam maioria suficiente para o andamento dos projetos no governo. A situação seria ora de não-governabilidade, ora de "traição" ao partido ou aos ideais revolucionários. Na perspectiva do autor, esse dilema deveria ser equacionado por um forte sistema de alianças. Ao contrário de Przeworski, Esping-Andersen não acredita que uma aliança estratégica condenaria e levaria à derrota um esforço social-democrata para o poder. Sua proposta passa pela construção da unidade e do consenso. A possibilidade de políticas sociais efetivas estaria eminentemente ligada ao grau de consenso político e coesão social da sociedade. 
A idéia de estrutura de classes junto à formação de classes está, segundo o autor, estritamente relacionada à implementação de um projeto socialista democrático. A primeira, resultado de transformações históricas concretas, fruto do processo de divisão do trabalho moderno. A segunda, a formação de classes, consistiria em dar uma identidade coletiva para um agregado heterogêneo que, quando não organizado em classe, tenderia a votar com base em outras fontes de identificação coletiva - como católicos, protestantes, mulheres, ecologistas, gays, entre outras.

A possibilidade de se transformar uma população diferenciada em uma comunidade coesa envolve, segundo o autor, uma combinação de movimento de organização e política de Estado (Esping-Andersen, 1985, p. 32). De imediato, havia a necessidade de uma vitória nacionalmente centralizada e verticalmente organizada, que implementasse o processo de unificação que impediria uniões de natureza excludente.

O "modelo escandinavo" abordado em sua pesquisa é interessante e, segundo o autor, único, pois cedo (1870-1914) possibilitou uma aliança precoce entre camponeses e trabalhadores no esforço pela democracia. O que na prática tornou possível uma democracia perfeitamente estabelecida, mesmo no conturbado e instável período do entreguerras. No pós-guerra, segundo o autor, os social-democratas já eram praticamente dominantes ${ }^{5}$.

No período pós-70, contudo, os partidos políticos mostraram fortes sinais de decomposição ou, no mínimo, de estagnação. Esse período indicou que a fórmula política de um passado recente começava a perder o seu apelo e relevância. Um conjunto de políticas e a necessidade de uma nova composição política pareciam claros e iminentes. Para Esping-Andersen, "a necessidade de trazer grupos de trabalhadores de classe média para uma aliança democrática é urgente" (idem, p. 71 - tradução minha).

$\mathrm{Na}$ perspectiva de Esping-Andersen, há atualmente uma forte ruptura na tradição escandinava democrática do partido como elemento representativo de classe. O declínio de sua capacidade de representar interesses coletivos, formular programas, ideologias e agendas políticas coerentes estaria relacionado simultaneamente à fragmentação da base eleitoral e a sua incapacidade de mobilizar novas gerações de eleitores, isto porque "onde esquemas privados e profissionais proliferam, identidade coletiva e lealdade a esquemas públicos serão facilmente evaporados" (idem, p. 149 - tradução minha).

O estabelecimento do Welfare State estava de acordo com a idéia de reforma social como mobilizador político. Nesse caso, a sociedade, via Estado, assumiria a responsabilidade de prover e garantir os níveis de bem- 
estar em saúde, educação e assistência social de todos os membros da sociedade antes que grupos sociais, famílias ou o próprio mercado. Este fora visto, vale lembrar, como um elemento incompatível com o universalismo proposto pelas políticas sociais do modelo social-democrata.

$\mathrm{O}$ argumento de Esping-Andersen é que, para manter um alto grau de universalismo, distribuição dos recursos e políticas públicas eficazes, é necessário haver uma grande taxação. Essa política tributária, no entanto, recairia de maneira desproporcional e asfixiante sobre os segmentos sociais médios, o que inevitavelmente enfraqueceria politicamente o Estado e, conseqüentemente, as políticas públicas por ele implementadas. Segundo o autor, a saída para resolver o problema de incompatibilidade é estabelecer um efetivo controle político sobre o crescimento econômico. Nesse contexto, por exemplo, o desemprego é visto como um elemento que aumenta a incidência de problemas sociais; o emprego, o crescimento do poder aquisitivo e econômico, ao contrário, são vistos como elementos catalisadores e maximizadores da estabilidade política e do status quo. O fato é que o universalismo e a institucionalização do Estado de Bem-estar podem ser vistos, segundo o autor, como princípios básicos para a implementação de políticas sociais eficazes na saúde pública e na educação.

O que deve ser notado é que a ascensão de novos segmentos sociais impõe novas condições para as alianças e programas políticos de classe. A dificuldade de se perceber politicamente as sutilezas da nova estrutura social provoca obstáculos importantes para os partidos políticos e para a gerência do poder nas sociedades contemporâneas. Esping-Andersen pensa que é possível construir um novo mundo de solidariedade social e política eficaz entre o eleitorado, que ajudaria a sustentar um projeto social democrático inovador. Para tanto, deve ser observada uma espécie de encruzilhada histórica, similar à da década de 1930 nas sociedades escandinavas. Lá, o camponês foi a chave para a futura social-democracia. Hoje, nas sociedades modernas ocidentais, segundo ele, são os setores de classe média em ascensão (white-collar strata), das áreas técnica, administrativa e de serviços, que ocupariam na estrutura social aquela posição política chave. Se há uma decomposição da social-democracia, ela reflete a incapacidade e a inabilidade do socialismo para constituir forte(s) aliança(s) fora do centro da anacrônica concepção de classe trabalhadora.

A lição que coloca, se é que assim podemos dizer, é que uma revolta contra a concepção de partido moderno pode ser vista, no mínimo, como um perigo à democracia. As mudanças sociais que fazem figurar os partidos 
Carlos Henrique Assunção Paiva

como elementos centrais na vida política não são meros acidentes e não devem ser ignoradas, sob o pretexto de poderem ser anuladas. Como mostrou Esping-Andersen, nas condições das sociedades de massas que surgiram gradualmente com o alvorecer do mundo moderno, o partido constitui, se não o único, pelo menos um dos meios mais acessíveis de se articular os desejos das imensas massas populares para os fins políticos.

A questão que o autor vem tentando conduzir não diz respeito à falta ou não de mobilização política das massas, mas sua fragmentação como comunidade ou coletividade. Para ele, se sustentarmos a idéia de guetto party como elemento de representação de unidades ou fragmentos sociais, a possibilidade de uma aliança renovadora, eficaz e coesa socialmente parecerá ainda uma utopia anacrônica.

O autor de Politcs against markets coloca a discussão das políticas públicas, num só tempo, na arena política e social. Política porque diz respeito à habilidade das lideranças mobilizarem novos segmentos sociais e novas gerações. Social porque percebe que essas transformações são demasiado complexas, pois dizem respeito à maneira como as pessoas se organizam e se relacionam socialmente, trabalham e se expressam, como constroem suas identidades num mundo tanto impessoal quanto fugaz.

\section{Considerações Finais}

Para Jacques Godbout, a intervenção estatal, via regulamentação jurídica, decretos ou leis, no âmbito das políticas públicas no mundo cotidiano das populações, pode produzir conflitos culturais ou até mesmo sociais. Segundo ele, os conflitos são conseqüências do fato de a política social estar muito além da esfera governamental - isto é, além de sua tentativa de alocar e distribuir bens e serviços. Escaparia, nesse sentido, ao cálculo econômico.

A prática governamental, na visão do autor, tenderia a se portar muitas vezes de forma totalitária, pois pretende transformar, com um só golpe (freqüentemente de caneta), instituições e organismos sociais em doadores e, eventualmente, certos indivíduos ou populações em receptores de bens e serviços. Num mesmo tempo, tal prática, como observa o autor, pretende acabar com as diferenças qualitativas de "quem doa" e de "quem recebe", pois elimina o espaço para o desejo (o desejo de dar, receber e retribuir). Nesse caso, a dádiva assume a temida perspectiva de gratuidade, perde seu estatuto social e seu caráter simbólico. A relação não é mais realizada entre pessoas, mas, em última instância, no caso da assistência médica, por exemplo, entre um aparelho burocrático estatal e um doente. 
$\mathrm{O}$ argumento de Godbout é relevante se estivermos interessados em observar as sutilezas de cada especificidade cultural que porventura possa influenciar ou mesmo prejudicar o andamento de determinada política pública e social em alguma comunidade ou segmento social. Mas pode ser demasiado ingênuo, se partirmos do princípio de que existe algo efetivamente agindo de forma universal, estrutural ou meta-histórica a favor de determinados segmentos sociais ou da sociedade como um todo. Algo que por si só fosse a garantia de distribuição de bens e serviços, independentemente dos acontecimentos sociais e históricos que determinada realidade impõe. Não é o que o autor propõe.

Quero ser muito claro a este respeito. A solidariedade, indispensável à efetivação das políticas públicas, não parece ser um atributo da "natureza humana". Se o é totalmente ou em parte, como sustentam alguns pensadores, não é uma área imutável e autônoma o bastante para que não se possa nela intervir. É preciso construir ou excitar, como queiram, um processo de reconhecimento entre as pessoas diante de um mundo público. A questão está - de Émile Durkheim, passando por Marcel Mauss até Jacques Godbout - tanto na arena política como na social.

Godbout, especificamente, fez ver que os grupos ou segmentos sociais alvos das políticas sociais não deveriam ser interpretados como "objetos" de uma intenção política ou econômica. É preciso que sejam reconhecidos como "sujeitos ativos" da relação, na mesma medida em que tenham a capacidade de reconhecer o Estado, ou qualquer outro segmento social, não como "alguém" que apenas dá gratuitamente. O que parece faltar é, segundo o autor, uma certa consciência de interatividade social e de existência de um mundo público.

Por isso, segundo o autor de L'esprit $d u$ don, não seria conveniente, com o risco de sermos ingênuos, reconhecer em um Estado autônomo, perante a passividade das massas, fenômeno típico nas sociedades do Leste Europeu do pós-guerra, o elemento responsável pelo aumento nos índices de qualidade de vida, sobretudo nos países industrializados. No entanto, vale lembrar, não podemos desconsiderar que determinado plano da sociedade ou das relações sociais deve ser regulado pelo contrato social. Sobretudo quando tratamos a questão da inclusão/exclusão, da convivência ou da coabitação.

O Estado, juntamente com a atividade dos sindicatos, partidos políticos e movimentos sociais diversos, pôde representar a garantia de bem-estar e emprego em algumas regiões do globo (ver Hobsbawm, 1995; EspingAndersen, 1985). A crise do modelo de Keynes representou na esfera social 
a ruptura dos laços de solidariedade entre Estado e sociedade - mais precisamente, entre Estado e trabalhadores. Por isso, a lógica keynesiana clássica, de manutenção de uma taxa de desemprego baixa, foi posta de lado. O mais importante parecia ser a manutenção da inflação sob controle. As políticas sociais passaram a ser lidas como políticas econômicas ("o problema da saúde é um problema econômico"), pois a prioridade dos anos 70 aos dias de hoje parece ser o combate ao déficit público, mesmo que isso signifique cortes em programas sociais que seriam considerados excessivos.

Na visão de Eric Hobsbawm (1995), o Estado deve ser observado como uma instituição importante rumo às garantias sociais para o estabelecimento da cidadania, sobretudo na primeira metade do século. As transformações políticas e sociais que ocorrem no seio da organização estatal, a partir da segunda metade do século XX, dão-lhe novo estatuto. A guinada de um Estado-providência para um liberal se fez acompanhar de mudanças correspondentes (mas não conseqüentes) importantes no mundo da cultura. Tanto do ponto de vista políticoeconômico como também da cultura e das ideologias dominantes parece chegarse a um assustador consenso (tautológico) de que "flexibilidade" e "autonomia" são indiscutivelmente uma saída universal para todos os problemas sociais, incluindo de saúde pública, e econômicos, independentemente das particularidades e especificidades culturais e sociais que porventura possam existir. Nesse caso, descartam-se as realidades sociais (simbólicas) de comunidades ou segmentos sociais específicos como elementos analíticos. Nesse sentido, Jacques Godbout parece ter absoluta razão.

Por isso, um dos argumentos de Eric Hobsbawm (1995) não deve ser abandonado. É preciso notar que "flexibilidade" em países que tiveram um Welfare State é uma coisa; mas qual o impacto naqueles países, como os latino-americanos, que nunca tiveram propriamente um Estado de Bemestar, isto é, um Estado que em determinado contexto social cumpriria certos dispositivos da legislação social? Saúde pública é, afinal, um problema público ou individual? A noção saúde/doença, nesse contexto, pode perder sua dimensão interativa para se transformar em mero problema individual.

Fala-se em globalização e flexibilidade, principalmente, das perspectivas francamente utilitaristas que apontam o fardo burocrático do Welfare State como limite para a eficiência e a inovação. Os governantes, políticos e administradores parecem pensar via uma lógica de antagonismos. Na esfera do mercado, teríamos, de um lado, os produtores; e de outro, os consumidores. Na esfera política, as instituições; de outro, os contribuintes. Os parâmetros e fatores sociais são, como foi dito, habitualmente ignorados. 
É preciso ficar claro que, no chamado período de ouro do capitalismo ocidental (as três décadas que seguem o pós-guerra), a questão social foi mantida sob razoável controle, não porque estavam todos absolutamente satisfeitos e sem dificuldades, mas graças à conjunção de alguns elementos inter-relacionados que parecem cada vez mais escassos nos dias de hoje. Primeiro, desenvolveu-se, sobretudo nos países industrializados, um eficiente sistema público de assistência social. Segundo, famílias ou comunidades padronizadas eram capazes de fornecer uma rede de auxílio para indivíduos em dificuldade (Hobsbawm, 1995; Castel, 1991).

O ponto é que afirmar ou constatar a existência de uma realidade social ou macrossocial não é um convite à inércia ou à falta de compromisso com o coletivo. A decisão e o processo de mudança têm que obrigatoriamente passar pela esfera das opções individuais. Nesse ponto, Herbert Marcuse (1968) tinha absoluta razão. O esforço desse trabalho foi no sentido de restituir uma realidade coletiva, pois acredito que, pelo menos genericamente, os problemas por que passa a maioria dos indivíduos modernos estão relacionados à carência de um mundo público que tende a ser saqueado e privatizado. De imediato, no entanto, cabe aos indivíduos, segmentos sociais, governantes, lideranças políticas e mesmo religiosas darem conta explicitamente disso. A reação, vamos chamar assim, deverá tomar uma dimensão política, moral e subjetiva.

Se as autoridades políticas, como vimos, se mobilizarem via imposição de leis ou decretos não sintonizados com a realidade social dos grupos sociais (com suas realidades simbólicas), isso se revelará inoperante, quando não intolerável às pessoas. Parece ser mais que oportuno, nesse momento, estar atento aos sistemas de solidariedade vigentes e, principalmente, aos sistemas sociais, econômicos e políticos que parecem desafiá-los. Para Castoriadis, por exemplo, o imaginário seria uma das condições da funcionalidade, um dos elementos da criação na história. Segundo ele, "as leis podem realizarse utilizando as ilusões dos indivíduos" (1982, p. 160 - grifo meu).

Concluindo, é preciso ficar claro que a compreensão do processo de exclusão social que se opera parece estar relacionada ao conhecimento da história moderna das sociedades ocidentais, inclusive as especificidades de cada região ou segmentos sociais. A construção dos atores sociais não é arbitrária, nasce no processo histórico. A necessidade de algum rompimento com o presente não é a negação da história. É o apelo à mudança. A promessa de rompimento com uma realidade que julgamos inaceitável não deve ficar ao sabor das realidades macrossociais, como 
se estas fossem alheias aos nossos interesses pessoais. A revolução que se espera não deverá ocorrer no âmbito das leis ou das armas, mas no estabelecimento de novos atores sociais: os cidadãos, em lugar de meros indivíduos.

\section{Notas}

* Este artigo é uma versão de um capítulo da dissertação de mestrado Solidariedade: uma abordagem teórica dos vínculos sociais modernos, defendida em outubro de 1999, no Instituto de Medicina Social/UERJ. O autor agradece a valiosa contribuição do professor Luiz Antonio de Castro Santos.

1 Bacharel e licenciado em História pelo Instituto de Filosofia e Ciências Humanas/UERJ, mestre e doutorando em Saúde Coletiva no Instituto de Medicina Social/UERJ.

2 Sua expressão política ideal, seguramente, está em Margaret Thatcher: "Não há sociedade, só indivíduo." (ver Hobsbawm, 1995).

3 Para Peter Marris (1996), as relações primárias (as da infância), o attachment aos pais, são as interações mais importantes para o desenvolvimento dos significados sociais e da estrutura cognitiva para o resto da vida dos indivíduos. Para Castoriadis (1982, p. 127), a constituição da subjetividade estaria relacionada à noção de "suporte". Segundo ele, "o que chamamos de suporte não é o simples suporte biológico, é o fato de que um conteúdo qualquer já está sempre presente e não é resíduo, escória, obstáculo ou matéria indiferente, mas condição eficiente da atividade do sujeito. Esse suporte, esse conteúdo, não é nem simplesmente do sujeito, nem simplesmente do outro (ou do mundo). É a união produzida e produtora de si e do outro (ou do mundo)".

4 Gilberto Hochman, em A era do saneamento, demonstra claramente como a consciência de interatividade social provocada pelas doenças e epidemias, que assolavam nosso país nas primeiras décadas do século XX, repercutiu em instituições sociais e políticas públicas no campo da saúde.

5 O autor chama a atenção também para o fato de o consenso e a unidade política e social terem sido bem-sucedidos em função da homogeneidade étnica, lingüística e cultural daqueles países. Para ele, foram fatores que reduziram a possibilidade de clivagens nas sociedades escandinavas.

\section{Referências Bibliográficas}

BARRACLOUGH, G. Introdução à história contemporânea. Tradução de Álvaro Cabral. Rio de Janeiro: s.n., 1973. 252 p.

BELL, D. The coming of post-industrial society. A venture in social forecasting. New York: Basic Books, 1976. 489 p.

CASTEL, R. De 1'indigence à l'exclusion, la désaffiliation. Précarité du travail et vulnérabilité relationnelle. In: DONZELOT, J. (Org.). Face à l'exclusion, le modèle français. Paris: Éditions Esprit, 1991. p. 137-168. CASTORIADIS, C. A instituição imaginária da sociedade. 2. ed. Tradução de Guy Reynaud. Rio de Janeiro: Paz e Terra, 1982. 418 p. 
DURKHEIM, E. Da divisão do trabalho social. Tradução de Eduardo Brandão. São Paulo: Martins Fontes, 1995. 483 p.

ELIAS, N. A sociedade dos indivíduos. Tradução de Vera Ribeiro. Rio de Janeiro: Zahar, 1994. 201 p.

ESPING-ANDERSEN, G. Politics against markets. The social democratic road to power. New Jersey: Princeton University Press, 1985. $324 \mathrm{p}$.

GODBOUT, J. T. L'esprit du don. Paris: Editions la Découverte, 1992. 343 p.

HOBSBAWM, E. Era dos extremos. O breve século XX (1914-1991). 2. ed. Tradução de Marcos Santarrita. São Paulo: Companhia das Letras, 1995. $598 \mathrm{p}$.

HOCHMAN, G. A era do saneamento. São Paulo: Hucitec, 1998. 261 p.

MARCUSE, H. Eros e civilização. Uma crítica filosófica do pensamento de Freud. Tradução de Álvaro Cabral. Rio de Janeiro: Zahar, 1968. 232 p.

MARRIS, P. The politics of uncertainty. Attachment in private and public life. London: TJ Press, 1996. 186 p.

MAUSS, M. Ensaio sobre a dádiva. Tradução de Antônio Filipe Marques. Lisboa: Edições 70, [s.d.]. 209 p.

MINGIONE, E. Fragmentação e exclusão: a questão social na fase atual de transição das cidades nas sociedades industriais avançadas. Dados. Revista de Ciências Sociais, Rio de Janeiro, v. 41, n. 4, p. 673-700, 1998.

PRZEWORSKI, A. Capitalismo e social-democracia. Tradução de Laura Teixeira Motta. São Paulo: Companhia das Letras, 1987. 65 p. SAID, E. Cultura e imperialismo. Tradução de Denise Bottman. São Paulo: Companhia das Letras, 1985. 459 p.

SENNETT, R. O declínio do homem público. As tiranias da intimidade. Tradução de Lygia Araújo Watanabi. São Paulo: Companhia das Letras, 1995. $447 \mathrm{p}$. 


\section{ABSTRACT}

Solidarity, politics and power: challenging public policies

This article discusses some meanings associated with the concept of solidarity. The themes of social support and social justice are particularly focused, as the intellectuals of the same current of thought turned against social exclusion and towards democracy and social solidarity. It is proposed that the absence of social solidarity is linked to the decline of public support and social assistance systems and institutions in modern Western societies. From the conjunction of ideas of solidarity in time and space, the possibility of strong solidarity ties in social life can be developed.

Keywords: Social solidarity; public policy; social work.

\section{RÉSUMÉ}

Solidarité, politique et pouvoir: le défi aux politiques publiques

Cet article discute quelques sens atribués à la solidarité. On privilégie ceux où le soucis avec le thème du soutien et de la justice sociale se trouve plus particulièrement. Voilà pourquoi on cherche plus attentivement les propositions des intellectuels contemporains qui peuvent être rejoints à une ligne de pensée liée au thème de la démocratie, incorporation et solidarité sociale. On propose que le déclin des liens de cohésion social se rapporte, à son tour, au déclin des systèmes et institutions de soutien et assistance sociale dans les sociétés occidentales modernes. On essaie de montrer que la possibilité d'une forte cohésion dans la vie en société vient de l'idée de solidarité dans l'espace et dans le temps.

Mots-clé: Solidarité sociale; politiques publiques, assistance sociale.

Recebido em 14/08/00.

Aprovado em 27/10/00. 